\title{
Automated systems in the identification and determination of methicillin resistance among coagulase negative staphylococci
}

\author{
Juliana Caierão, Silvana Superti*, Cícero AG Dias, Pedro Alves d'Azevedo/ ${ }^{+}$
}

\author{
Departmento de Microbiologia e Parasitologia, Fundação Faculdade Federal de Ciências Médicas de Porto Alegre, \\ Rua Sarmento Leite 245/211, 90050-170 Porto Alegre, RS, Brasil *Laboratório de Bacteriologia do Hospital Mãe de Deus, \\ Porto Alegre, RS, Brasil
}

\begin{abstract}
Coagulase-negative staphylococci (CoNS) are an important cause of nosocomial bacteremia, specially in patients with indwelling devices or those submitted to invasive medical procedures. The identification of species and the accurate and rapid detection of methicillin resistance are directly dependent on the quality of the identification and susceptibility tests used, either manual or automated. The objective of this study was to evaluate the accuracy of two automated systems - MicroScan and Vitek - in the identification of CoNS species and determination of susceptibility to methicillin, considering as gold standard the biochemical tests and the characterization of the mecA gene by polymerase chain reaction, respectively. MicroScan presented better results in the identification of CoNS species (accuracy of 96.8 vs $78.8 \%$, respectively); isolates from the following species had no precise identification: Staphylococcus haemolyticus, S. simulans, and S. capitis. Both systems were similar in the characterization of methicillin resistance. The higher discrepancies for gene mec detection were observed among species other than S. epidermidis (S. hominis, S. saprophyticus, S. sciuri, S. haemolyticus, S. warneri, S. cohnii), and those with borderline MICs.
\end{abstract}

Key words: coagulase-negative staphylococci - methicillin - automated systems

Coagulase-negative staphylococci (CoNS) become important nosocomial pathogens, being, in many institutions, among the main etiological agents of nosocomial bacteremias (Cockerill et al. 1997, Hussain et al. 1998, Petinaki et al. 2001). Many clinical laboratories do not identify CoNS in species level when these microrganisms are detected in blood or in cerebrospinal fluid. However, as the significance of CoNS as pathogens has been increased, it has become more important to know the epidemiology and the pathogenic potential of species, individually. This might be particularly important considering blood culture isolates, since it is often difficult to determine the clinical significance of an individual isolate. There are numerous commercial systems and kits available nowadays for the identification of CoNS species (Kloos \& Bannerman 1999).

Resistance to methicillin among these microrganisms is a matter of concern because of the high and increasing levels detected. In Brazil, a multicenter study showed that methicillin resistance was observed in $87.7 \%$ of CoNS isolated from bloodstream infections (Sader et al. 1999). The accurate detection of methicillin resistance among CoNS isolates in the clinical laboratory is important to guide therapy and to promote the correct use of glycopeptides (Hussain et al. 1998, Yamazumi et al. 2001).

This work was performed to evaluate the accuracy of two automated systems in the identification of species

\footnotetext{
Financial support: CNPq, Capes

+Corresponding author: pedroaze @ fffcmpa.edu.br

Received 25 November 2005

Accepted 18 April 2006
}

and determination of methicillin resistance, considering as gold standard the conventional biochemical tests and the characterization of mecA gene by polymerase chain reaction $(\mathrm{PCR})$, respectively.

\section{MATERIALS AND METHODS}

Bacterial samples - Ninety-four consecutive CoNS isolates were included in the study, coming from blood cultures of patients hospitalized in the Complexo Hospitalar Irmandade Santa Casa de Misericórdia in Porto Alegre. The isolates were kept at $-20^{\circ} \mathrm{C}$ in skim milk (Difco), plus $20 \%$ glycerol. The quality control of the tests was done using the Staphylococcus hominis ATCC 27844, S. epidermidis ATCC 12228, S. saprophyticus CCM 883, S. haemolyticus CCM 2737, and S. aureus ATCC 33591.

Identification of bacterial isolates by conventional biochemical tests - The isolates were identified by conventional biochemical tests based on Manual for Clinical Microbiology (Bannerman 2003). The following test were used: catalase test, coagulase test, clumping factor, urease activity, ornitine decarboxilation, PYRase activity, presence of hemolysis, phosphatase activity, and fermentation of carbohydrates.

Determination of susceptibility to methicillin - Susceptibility to methicillin was determined by the characterization of mecA gene by PCR. The bacterial DNA was extracted by thermal lysis according to Nunes et al. (1999), and the PCR was performed according to Santos et al. (1999), with modifications. Briefly, primers mecA1 (5'TGGCTATCGTGTCACAATCG-3') and mecA2 (5'CTGGAACTTGTTGAGCAGAG-3') were used for amplification of a fragment of $310 \mathrm{pb}$ of the mecA gene. The solution for PCR, with a final volume of $50 \mu \mathrm{l}$, was composed of $10 \mu \mathrm{l}$ of extracted DNA, 50 pmolar of each primer, 
$250 \mu$ molar of each dNTP, $2 \mu \mathrm{l}$ of magnesium chloride, $5 \mu \mathrm{l}$ of the buffer of the enzyme, and $2.5 \mathrm{U}$ of Taq DNA polymerase. The total cycle of the amplification was composed of an initial denaturation stage at $94^{\circ} \mathrm{C} / 1 \mathrm{~min}$, followed by 30 cycles, with denaturation at $94^{\circ} \mathrm{C} / 15 \mathrm{~s}$, annealing at $55^{\circ} \mathrm{C} / 15 \mathrm{~s}$, and extension at $72^{\circ} \mathrm{C} / 5 \mathrm{~s}$. The amplification products were analyzed by electrophoresis in agarose gel at $1.5 \%$ in TBE $0.5 \mathrm{X}$, containing ethidium bromide $(0.5 \mu \mathrm{g} /$ $\mathrm{ml})$ at $130 \mathrm{~V}$ and photographed under ultraviolet light. As standard of electrophoretic running, the standard molecular weight of $100 \mathrm{pb}$ was used (Gibco, BRL). The strains $S$. aureus ATCC 33591 and $S$. aureus ATCC 25923 were used as positive and negative control, respectively.

Identification of species and methicillin susceptibility using automated systems - The identification of species and the methicillin susceptibility were determined using automated systems MicroScan (Dade Behring), panel PC-13, and Vitek, GPS-105 (bioMérieux). The manufacturer's instructions were followed for the preparation of the inoculum and period of incubation of isolates.

\section{RESULTS}

From the combination of the results of conventional biochemical tests, the 94 consecutive isolates of CoNS were identified as follows: $41 \mathrm{~S}$. epidermidis, $23 \mathrm{~S}$. haemolyticus, 20 S. hominis, 3 S. sciuri, 2 S. warneri, 2 S. saprophyticus, $2 \mathrm{~S}$. capitis, and $1 \mathrm{~S}$. simulans. The automated system MicroScan correctly identified 91 of the 94 isolates (accuracy of 96,8\%). One isolate of S. simulans was identified as S. hominis, 1 S. haemolyticus as S. auricularis, and 1 isolate of $S$. capitis was mistakenly char- acterized as S. hominis (Table I ). On the other hand, the automated system Vitek correctly characterized 74 of the 94 isolates (accuracy of 78.7\%), within 20 isolates mistakenly identified (Table I). The biochemical test that most frequently presented discordant results by the automated systems were the fermentation of mannose, threalose, and saccharose and the production of the urease enzyme. The characterization of methicillin resistance of the 94 samples $70(74.4 \%)$ presented the, mecA gene. This gene is proportionally more frequent in the S. haemolyticus species but was widely distributed across the other species (Table II). The discrepancies in the susceptibility tests are presented in Table III, showing the types of errors ("major" or "very major") presented by the automated systems. All isolates with false-positive results presented MICs of 0.5 or $1 \mu \mathrm{g} / \mathrm{ml}$, considered borderline (Table III).

TABLE II

Distribution of $m e c A$ gene among coagulase-negative staphylococci species

\begin{tabular}{lc}
\hline Species & mec \\
\hline S. gene $(\%)$ \\
S. epidermidis & 95.65 \\
S. hominis & 70.73 \\
S. sciuri & 65 \\
S. saprophyticus & 66 \\
S. capitis & 100 \\
S. warneri & 50 \\
S. simulans & 50 \\
\hline
\end{tabular}

S.: Sthaphylococcus

TABLE I

Results for the identification of isolates by the automated systems, compared to conventional identification

\begin{tabular}{|c|c|c|}
\hline Conventional identification & MicroScan identification & Vitek identification \\
\hline S. hominis $(\mathrm{n}=20)$ & S. hominis $(\mathrm{n}=20)$ & $\begin{array}{l}\text { S. } \text { hominis }(\mathrm{n}=9) \\
\text { S. } \text { simulans }(\mathrm{n}=2) \\
\text { S. } \text { epidermidis }(\mathrm{n}=5) \\
\text { S. } \text { saprophyticus }(\mathrm{n}=1) \\
\text { S. } \text { cohnii }(\mathrm{n}=1) \\
\text { S. } \text { capitis }(\mathrm{n}=1) \\
S . \text { auricularis }(\mathrm{n}=1)\end{array}$ \\
\hline S. epidermidis $(\mathrm{n}=41)$ & S. epidermidis $(\mathrm{n}=41)$ & $\begin{array}{l}\text { S. epidermidis }(\mathrm{n}=40) \\
\text { S. hominis }(\mathrm{n}=1)\end{array}$ \\
\hline S. haemolyticus $(\mathrm{n}=23)$ & $\begin{array}{l}\text { S. haemolyticus }(\mathrm{n}=22) \\
\text { S. auricularis }(\mathrm{n}=1)\end{array}$ & $\begin{array}{l}\text { S. haemolyticus }(\mathrm{n}=22) \\
\text { S. simulans }(\mathrm{n}=1)\end{array}$ \\
\hline S. sciuri $(\mathrm{n}=3)$ & S. sciuri $(\mathrm{n}=3)$ & $\begin{array}{l}\text { S. sciuri }(\mathrm{n}=1) \\
\text { S. hominis }(\mathrm{n}=1) \\
\text { unidentified org }(\mathrm{n}=1)\end{array}$ \\
\hline S. simulans $(\mathrm{n}=1)$ & S. hominis $(\mathrm{n}=1)$ & S. haemolyticus $(\mathrm{n}=1)$ \\
\hline S. warneri $(\mathrm{n}=2)$ & S. warneri $(\mathrm{n}=2)$ & $\begin{array}{l}\text { S. simulans }(\mathrm{n}=1) \\
\text { S. hominis }(\mathrm{n}=1)\end{array}$ \\
\hline S. saprophyticus $(\mathrm{n}=2)$ & S. saprophyticus $(\mathrm{n}=2)$ & S. saprophyticus $(\mathrm{n}=2)$ \\
\hline S. capitis $(\mathrm{n}=2)$ & $\begin{array}{l}\text { S. capitis }(\mathrm{n}=1) \\
\text { S. hominis }(\mathrm{n}=1)\end{array}$ & Unidentified org. $(n=2)$ \\
\hline
\end{tabular}


TABLE III

Discrepancies in the susceptibility tests and type of error presented, using as gold standard presence or absence of $m e c A$ gene

\begin{tabular}{|c|c|c|c|c|c|}
\hline \multirow[b]{2}{*}{ Isolate } & \multirow[b]{2}{*}{ mecA } & \multicolumn{2}{|c|}{ MicroScan } & \multicolumn{2}{|c|}{ Vitek } \\
\hline & & Phenotype & Error & Phenotype & Error \\
\hline Staphylococcus hominis $(\mathrm{n}=3)$ & Pos & S & M & $S$ & M \\
\hline S. saprophyticus $(\mathrm{n}=2)$ & Pos & $\mathrm{S}$ & $\mathrm{M}$ & $\mathrm{S}$ & M \\
\hline S. sciuri $(\mathrm{n}=2)$ & Pos & $\mathrm{S}$ & $\mathrm{M}$ & $\mathrm{S}$ & M \\
\hline S. haemolyticus $(\mathrm{n}=1)$ & Pos & $\mathrm{S}$ & M & $\mathrm{R}$ & - \\
\hline S. saprophyticus $(\mathrm{n}=2)$ & Neg & $\mathrm{R}$ & VM & $\mathrm{R}$ & VM \\
\hline S. warneri $(\mathrm{n}=2)$ & Neg & $\mathrm{R}$ & VM & $\mathrm{R}$ & VM \\
\hline S. cohnii $(\mathrm{n}=1)$ & Neg & $\mathrm{R}$ & VM & $\mathrm{R}$ & VM \\
\hline S. haemolyticus $(\mathrm{n}=1)$ & Neg & $\mathrm{R}$ & VM & $\mathrm{R}$ & VM \\
\hline S. hominis $(\mathrm{n}=2)$ & Neg & $\mathrm{S}$ & - & $\mathrm{R}$ & VM \\
\hline
\end{tabular}

S: susceptible; R: resistant; M: major error; VM: very major error

The automated system MicroScan characterized as resistant $62(88.57 \%)$ of the 70 samples that carried the mecA gene. Of the 8 false-positive results, 3 were $S$. hominis, $1 \mathrm{~S}$. haemolyticus, $2 \mathrm{~S}$. saprophyticus, and 2 belonged to the $S$. sciuri species. The 6 false-positive results were distributed as follows: $2 S$. saprophyticus, $2 S$. warneri, $1 \mathrm{~S}$. haemolyticus, and $1 \mathrm{~S}$. cohnii. In the automated system Vitek, 63 (90\%) samples were correctly characterized as resistant. The same 3 isolates of $S$. hominis, 2 S. saprophyticus, and $2 S$. sciuri falsely characterized as susceptibile by the MicroScan system also showed falsepositive results by the Vitek. The false-positive isolates by the MicroScan system also showed false-positivel results by the Vitek. Moreover, 2 isolates of S. hominis were also phenotypically resistant even without the presence of the mecA gene in their genome.

\section{DISCUSSION}

CoNS are the microorganisms most commonly isolated from blood cultures, representing a serious health problem in many developing countries and also in developed ones (Renneberg et al. 1995). So, there are, in the literature, many works discussing this issue. Cunha et al. (2004) present two methods modified in their laboratory to manually identify CoNS and they conclude that methods were found to be highly efficient for routine use due to their high sensitivity and specificity compared to the reference method (biochemical tests proposed by Bannerman in 2003), requiring fewer tests and thus being more economical and faster than the standard method. Here, we discuss the accuracy of automated systems, once they are faster than manual tests, being appropriate for routine laboratory. In general, the automated system MicroScan proved to be more accurate in the identification of CoNS species (accuracy of 96.8 vs $78.7 \%$, respectively). However, the discrepant results in the identification are related to species which are less frequently isolated, considering that for the 2 most frequent isolated and more clinically relevant species $-S$. epidermidis and S. haemolyticus - the systems had similar performances. As a result of the low correlation between the presence of the mecA gene in $S$. epidermidis and the results of the disk diffusion test and the determination of MIC (York et al. 1996, Tenover et al.
1997), the NCCLS (1999) changed the methicillin breakpoints for CoNS isolates. Thus, automated systems had to modify their software so that they fit the new breakpoints and can effectively detect methicillin resistance among CoNS isolates. The systems presented good performance in the determination of methicillin resistance, especially for S. epidermidis. On the other hand, the interpretative criteria of the NCCLS (2004), strains related to serious infections with MICs varying from 0.5 to 2 $\mu \mathrm{l} / \mathrm{ml}$ must be tested for the presence of the mecA gene or for the protein expressed by the gene, considering that they may present doubtful phenotypes. Considering that nowadays less frequent species of CoNS have been related to serious infections in hospital institutions, and that these have increasingly been isolated, it is very important to use automated systems which are accurate for the identification of these and for the determination of susceptibility to methicillin, leading to more rational therapy. In the present study, the MicroScan system was more accurate in the identification of CoNS strains and both presented limitations in the characterization of methicillin resistance in less frequent species.

\section{ACKNOWLEDGEMENTS}

To Dade Behring, to the staff of Central Laboratory of the Complexo Hospitalar Santa Casa of Porto Alegre.

\section{REFERENCES}

Bannerman TL 2003. Staphylococcus, Micrococcus, and other catalase-positive cocci that grow aerobically. In PR Murray, EJ Baron, JH Jorgensen, MA Pfaller, RH Yolken (eds), Manual of Clinical Microbiology, American Society of Microbiology, Washington, p. 384-404.

Cockerill FR, III JG, Hughes EA, Vetter EA, Mueller AR, Weaver AL, Ilstrup DM, Rosemblalt JE, Wilson WR 1997. Analysis of 281797 consecutive blood cultures performed over an eight-year period: trends in microorganisms isolated and the value of anaerobic culture of blood. Clin Infect Dis 24: 403-418.

Cunha ML, Sinzato RS, Yuri K, Silveira LVA 2004. Comparison of methods for the identification of coagulase-negative staphylococci. Mem Inst Oswaldo Cruz 99: 855-860.

Hussain Z, Stoakes L, Lannigan R, Longo S, Nancekivell B 
1998. Evaluation of screening and commercial methods for detection of methicillin resistance in coagulase-negative staphylococci. J Clin Microbiol 36: 273-274.

Kloos WE, Bannerman TL 1999. Staphylococcus and Micrococcus, In Murray PR, Baron EJ, Pfaller MA, Tenover FC, Yolken RH (eds), Manual of Clinical Microbiology, 7th ed., ASM Press, Washington DC, p. 264-282.

Nunes ELC, Santos KRN, Mondino PJJ, Bastos MCF, Giambiagi-de Marval M. 1999. Detection of ileS-2 gene encoding mupirocin resistance in methicillin-resistant Staphylococcus aureus by multiplex PCR. Diagn Microbiol Infect Dis 34: 77-81.

NCCLS-National Committee of Clinical Laboratory Standards. 2004. Performance Standards for Antimicrobial Susceptibility Testing: Fourteenth Informational Supplement. Wayne, Pennsylvania.

Petinaki E, Kontos F, Miriagou V, Maniati M, Hatz F, Maniatis AN, The bacterial resistance group 2001. Survey of methicillin-resistant coagulase-negative staphylococci in the hospitals of central Greece. Int J Antimicrob Agents 18: 563566.

Renneberg J, Rieneck K, Gutschik E 1995. Evaluation of Staph ID system and Staph Zym system for identification of coagulase-negative staphylococci. J Clin Microbiol
33: 1150-1153.

Sader HS, Sampaio JLM, Zocolli C, Jones RN 1999. Results of the 1997 SENTRY antimicrobial surveillance program in three Brazilian medical centers. Braz J Infect Dis 3: 63-79.

Santos KRN, Teixeira LM, Leal GS, Fonseca LS, Gontijo Filho PP 1999. DNA typing of methicillin-resistant Staphylococcus aureus: isolates and factors associated with nosocomial acquisition in two Brazilian university hospitals. J Med Microbiol 48: 17-23.

Tenover FC, Jones RN, Swenson JM, Zimmer B, McAllister S, Jorgensen JH, the NCCLS Staphylococci Working Group 1999. Methods for improved detection of oxacillin resistance in coagulase-negative staphylococci: results of a multicenter study. J Clin Microbiol 37: 4051-4058.

Yamazumi TIF, Diekema DJ, Pfaller MA, Jones RN 2001. Comparison of the Vitek gram-positive susceptibility 106 Card, the MRSA-Screen latex agglutination test, and mecA analysis for detecting oxacillin resistance in a geographically diverse collection of clinical isolates of coagulase-negative staphylococci. J Clin Microbiol 39: 3633-3636.

York MK, Gibbs F, Chehab S, Brooks GF 1996. Comparison of PCR detection of mecA with standard susceptibility testing methods to determine methicillin resistance in coagulasenegative staphylococci. J Clin Microbiol 34: 249-253. 